\title{
ENSAYO CONTRA EL FATALISMO DE LA NACIÓN COLOMBIANA: LA HISTORIOGRAFÍA Y EL INFALIBLE SENTIDO POLÍTICO DE LAS GUERRAS CIVILES DEL SIGLO XIK'
}

\author{
Óscar Mauricio Pabón Serrano² \\ Universidad Santo Tomás - Bucaramanga
}

\begin{abstract}
Resumen
Un capítulo central de la Historia Política de Colombia durante el siglo XIX, está constituido por las numerosas guerras civiles acontecidas en el territorio nacional, las cuales llevaron al enfrentamiento armado a civiles, militares y líderes de origen variopinto. A primera vista, los motivos de la guerra evidencian aspectos de cualquier índole relacionados con la vida en sociedad; pero al realizar un análisis y consenso profundo desde la perspectiva historiográfica, no cabe duda que todos los motivos de lucha adquirieron un sentido político en la medida que expresaron disputas por los elementos centrales que hicieron parte de la construcción del Estado-nación colombiano. Así las cosas, el siguiente artículo se presenta como el resultado de la revisión historiográfica sobre el tema de las guerras civiles y la caracterización de su sentido político.
\end{abstract}

\section{Palabras clave}

Guerras Civiles, Historiografía, Colombia, Estado-Nación, Política.

\section{ESSAY AGAINST THE FATALISM OF THE COLOMBIAN NATION: THE HISTORIOGRAPHY AND THE INFALLIBLE POLITICAL SENSE OF THE 19TH GENTURY GIVIL WARS}

\begin{abstract}
Alsitract
A central chapter of the Political History of Colombia during the 19th century is constituted by the numerous civil wars that took place in the national territory, which took civilians, military and leaders of different origins to armed confrontation. At first sight, the reasons for the war demonstrate aspects of any nature related to life in society; but when carrying out a deeper analysis and consensus from the historiographical perspective, there is no doubt that all the reasons for the fight acquired a political sense in the way that they expressed disputes for the central elements that were part of the construction of the Colombian nation state. Thus, the following article appears as the result of the historiographical revision on the subject of civil wars and the characterization of their political sense.
\end{abstract}

\section{Key Words}

Civil Wars, Historiography, Colombia, Nation State, Politics

1 Artículo de revisión historiográfica.

2 Egresado de la Escuela de Historia de la Universidad Industrial de Santander, Magíster en Historia de la misma Institución e investigador de la Historia Política y Militar del siglo XIX. Profesor del Departamento de Humanidades de la Universidad Santo Tomás y asesor de calidad en Educación Superior de las Unidades Tecnológicas de Santander; en el 2010 fue unos de los ganadores de la convocatoria Becas Bicentenario en el área de literatura, modalidad ensayo histórico; y en el 2009 ganó el Concurso Nacional de Ensayo Histórico "Historias Locales", convocado por la Alta Consejería Presidencial para el Bicentenario de la Independencia. promauricioserrano@hotmail.com 


\section{Introducción}

Algunos historiadores e intelectuales sumieron el destino de la nación colombiana en la fatalidad y destrucción, vieron la violencia como un atributo ontológico de los colombianos, redujeron las guerras civiles del siglo XIX a la dimensión de lo inhumano y al "espíritu violento" supuestamente insuflado en este desdichado pueblo. EI sentido político de las guerras civiles se desvirtuó a cambio de cierta constitución violenta de la sociedad y de la historia, olvidando que la guerra hizo parte del proceso de construcción del Estado-nación, desconociendo que la guerra se vinculó profundamente con los problemas de extensión de la ciudadanía, la exclusión electoral, la relación Iglesia-Estado y el caudillismo regional. Las guerras civiles deben comprenderse como una dimensión esencial de lo político y como una disparidad entre las opiniones que pugnaron por el control y la participación estatal.

El siguiente ejercicio historiográfico intenta desvirtuar el tema de la violencia como el carácter inmanente del pueblo colombiano, busca comprender desde una mirada en conjunto el sentido de las numerosas guerras civiles del siglo XIX. Primero, es necesario subrayar que la historiografía sobre las guerras civiles nos muestra un abultado balance. Varios estudios se centraron en el seguimiento de una guerra en específico y en el desarrollo regional de las guerras (Alonso Valencia, Javier Ortiz, Luis Prado, Francisco Zuluaga, Fernando Botero, Fabio Zambrano, Javier Díaz, Gonzalo España, Fernán González, Charles Berquist, Carlos Jaramillo), otros trataron de elaborar un trabajo de síntesis y comprensión integral (Gonzalo Sánchez, Thomas Fischer, Eduardo Posada, Fernán González, Malcolm Deas, Tirado Mejía, Marco Palacios, María Teresa Uribe). Teniendo en cuenta las investigaciones más relevantes sobre las guerras civiles se tratará de desarrollar el objetivo arriba expuesto.
En cuanto a la investigación histórica sobre los temas de la guerra, el conflicto y la violencia en Colombia, es sugerente destacar que con el final de la década de 1980 vino la consagración de un grupo de investigadores sociales cuyo tema fue la "violentología", fue así como las nociones de civilización y violencia, más sus corolarios, se acentuaron como las categorías opuestas a través de las cuales se quiso interpretar la historia colombiana. Estas categorías motivaron a muchos investigadores de lo social interesados en establecer las relaciones históricas entre las nombradas dicotomías (Daniel Pécaut, Gonzalo Sánchez, Darío Fajardo, Calos Perea y Cristina Rojas). Por ejemplo, el texto de Gonzalo Sánchez, Guerra y política en la sociedad colombiana, abordó algunas de las múltiples oposiciones y complementariedades de la memoria nacional, vinculando en diversos momentos la guerra y la política, una como continuación de la otra por otros medios.

En palabras de Gonzalo Sánchez, el siglo XIX fue el primer momento en el que yuxtaponen las categorías opuestas, siglo de intimas relaciones entre guerras civiles y política, "prácticas colectivas e indisociables". Sánchez señaló que la historia decimonónica colombiana se mueve entre guerras-batallas (de emancipación y catorce guerras civiles) y reformas-amnistías-constituciones. La guerra se interpretó como la fundadora del derecho y la institucionalidad, como el camino de las relaciones o el atajo para llegar a la política. Las guerras del siglo XIX no quebrantaron la tríada estructural de la "república señorial", formada por la Iglesia, las haciendas y los partidos políticos. Estos tres pilares controlaron el poder político y colombiano continúo como un "Estado crónicamente suplantado" por las potestades, impropio a la unidad nacional, a la solidaridad y regulación social (Sánchez, 1991). 
El sustrato de las guerras civiles demuestra los conflictos entre los grupos hegemónicos y élites regionales, solapados en los nacientes partidos políticos, la guerra no fue distintivamente revolucionaria, fue por la participación burocrática y por la exclusión-inclusión en el aparato institucional. En aquel contexto se declaró la guerra por desacuerdos en la organización política -centralista o federalista-; por discrepancias en cuanto al modelo de desarrollo económico; y por referencias a la relación Iglesia-Estado-Partidos, de la cual surgieron peligrosas alianzas. Resumiendo, para Sánchez estas guerras fueron todas inconclusas, ajenas a la victoria o a la derrota, culminadas en un "pacto horizontal". Guerras declaradas "para conversar" y hacer política, para negociar el armisticio y para fundar los gobiernos de unión, de alianza y lucha nuevamente latente, activadas por un carácter masivo aunque no popular (Sánchez, 1991).

Por su parte, Daniel Pécaut subrayó la falta de un relato nacional que sirva como referente de identidad para todos los colombianos, que articule al Estado en su totalidad y atenúe la valoración de la violencia fundacional. La violencia que acompañó procesos históricos como la conquista, la Independencia, las guerras civiles del XIX, las luchas partidistas y el conflicto con la insurgencia, constituye lo que se puede llamar nuestro mito fundacional. Pécaut vio en la violencia el aspecto que gestó la ausencia de nuestro relato identitario, el mito nacional se fundó en "la violencia de la representación", un carácter que regula la sociedad colombiana desde adentro y no confiere el valor que la guerra le obsequió a los Estados nacionales como los europeos a partir de la representación del enemigo externo. Explicó que la violencia que nos identifica es una construcción histórica que sustituye el relato armónico por un discurso fundacional soportado en la exclusión de la diferencia, en la mirada maniquea de una sociedad profundamente tradicional.
El estudio de las guerras civiles debe mirar hacia una referencia básica que facilite su comprensión. El proceso de Independencia puede considerarse como una escuela de guerra que rompió con la "calma colonial", desde 1810 se afianzó "el papel de la guerra en el proceso dinámico de definición de identidades". Los historiadores revisionistas de las Independencias (Francios-Xavier Guerra, Jaime Rodríguez, Manuel Chust, Clément Thibaud, Inés Quintero), además de opacar el carácter patriótico dado por las historias fundacionales a aquellas "gestas", coincidieron en afirmar que la separación de Hispanoamérica del dominio monárquico español fue un proceso absolutamente violento, admitiendo que el conflicto tomó la forma de guerra civil.

Clément Thibaud, influenciado por la tradición francesa y por la escuela weberiana, estudió los procesos de Independencia de la Nueva Granada y Venezuela, su investigación concibió la guerra como una experiencia que contribuyó a la construcción de ciudadanía e identidad. Manifestó que el proceso de emancipación produjo varias formas de hacer la guerra (desde la guerra irregular hasta la guerra de gran estilo), formas que a su vez generaron nuevas identidades, pues "la identidad de los actores evolucionó con la Forma de -hacer la- guerra". Las nuevas lecturas sobre la Independencia criticaron el carácter patriótico de la guerra, el proceso se interpretó más como una guerra civil, como la primera guerra que en la Nueva Granada cimentó la identidad guerrerista. Durante la Independencia la guerra popular se desvió en una multiplicidad de combates individuales, se declararon una serie de guerras privadas y se dio libre despliegue a los odios acumulados durante el periodo colonial o indiano. El proceso se transformó en una guerra civil en la que participaron todos los grupos dominados, dirigentes y élites regionales, en este periodo se borraron todas las diferencias y el régimen político se hundió en el caos (Thibaud, 2005: p. 339-364). 
El proceso de Independencia mostró que en adelante la guerra sería la táctica para llegar a otro orden o para instalarse en el nuevo Estado. La guerra generalizó la penuria y borró los límites morales, en este momento de caos se consiguió lo que no fue posible a través de la política negociada. Los caudillos, hijos de la lucha emancipadora, aprendieron que la guerra sería en lo sucesivo el medio para sus fines, su presencia indicó la existencia de un poder militar que intentó imponerse por medio de su oficio: la guerra. Tras la Independencia los hombres de las circunstancias quedaron descolocados, pero continuaron ejerciendo un liderazgo que lo accionaron a favor de sus intereses cuando las vías políticas de la nueva nación de ciudadanos no les funcionaron o convinieron.

Otro aspecto que fue consecuencia de la Independencia y posible causa de las Guerras Civiles fue la transición de regímenes, es decir, de la manera como los hombres serían mandados y gobernados. La reasunción forzada de la soberanía por parte del pueblo desde 1810, significó el tránsito de la política antigua a la política moderna. Las nuevas nociones de igualdad, ciudadanía, soberanía nacional y gobierno representativo se aplicaron bruscamente y marcharon en contra de la política antigua. La transición hacía la política moderna basada en un EstadoNación de ciudadanos -libres e iguales- se construyó a partir de la experiencia francesa, de esta manera el gran problema de construcción de la nación fue que este modelo resultó ajeno a la tradición hispánica. Así se optó por el camino de la nación en contra de las tradiciones seculares y la política corporativa, la tradición política obstaculizó la construcción -moderna- de la nación. La experiencia política de la modernidad fue incompatible con la política grupal-estamental, el nuevo sistema generó enormes malestares en una sociedad todavía acompasada por las permanencias políticas coloniales
(Guerra, 1998: p. 109-139) ${ }^{3}$. Las numerosas guerras civiles del siglo XIX fueron la consecuencia directa del choque entre la política moderna y tradicional.

La convocatoria a una nueva historia política colombiana, realizada por Armando Martínez, presentó las guerras civiles como uno de los temas básicos de investigación política. Sin embargo, Martínez enfatizó en que el tema de las guerras no se refiere "a algún singular desarreglo genético de los colombianos", sino a una manera de resolver el equilibrio de poderes en el entramado social o en el "esencial estar juntos de las personas diversas que comparten el mismo mundo histórico". En este sentido, ubicó a las guerras civiles entre los temas básicos de la historia política y negó su reducción a la "dimensión de lo inhumano". El sentido de las acciones militares fue esencialmente político, supuso la libertad para resolver un equilibrio de poderes enfrentados que no se resolvió por otras vías. La causa o el motivo central de las guerras deben buscarse en la disparidad de opiniones que el equilibrio de poderes no permitió negociar. Armando Martínez precisó el sentido político de las guerras civiles, no comparte la tesis del "espíritu violento" que los llamados violentólogos quisieron atribuir a los colombianos e implícitamente nos recuerda que según Clausewitz la guerra es la política continuada por otros medios (Martínez, 2005) ${ }^{4}$.

3 François-Xavier Guerra sugirió que "Es muy posible que, si se utilizan los instrumentos conceptuales adecuados, se confirma que el mundo hispánico representa una de las mayores variedades de la "política antigua", modalidad que explica su particular tipo de modernidad. La persistencia de una visión grupal de lo social, la tenaz tendencia al autogobierno y la correlativa dificultad de pensar y de construir el Estado y la sociedad civil sin duda encuentran ahí una de sus principales explicaciones".

4 Armando Martínez afirmó que "Las guerras civiles son entonces un tema básico de la vida política de los colombianos, es decir, de las relaciones que unos con otros tuvieron cuando sus disparidades no pudieron ser resueltas por la coacción del gobierno supremo 0 por la negociación argumentada. Los resultados de esas guerras deberían ser evaluadas en términos de los procesos de integración social de la nación o de los procesos del monopolio político del estado nacional. Con ello podrían superarse las habladurías sobre el supuesto carácter "violento" de los colombianos". 
Después de estas aclaraciones introductorias al tema de las guerras civiles colombianas durante el siglo XIX, se avanzará en la descripción de sus aspectos centrales, iniciando con la Guerra de Los Supremos y terminando con la guerra civil de 1885 que implicó la derrota del radicalismo liberal. La primera investigación que se referencia aquí es la de Fernando Botero Herrera, quien relacionó el problema de las guerras civiles, la invención de la región y la construcción de la nación.

El objetivo de Botero Herrera fue destacar "el papel de la guerra en la formación de la región y del Estado y viceversa". El autor no aceptó las explicaciones comunes de la historiografía antioqueña que afirmaron que las guerras fueron poco importantes en su historia regional, unas veces tratando de minimizar el papel de la guerra (Jorge Orlando Melo) y otras oponiendo un "proyecto civilista", político y económico antioqueño que evitó los conflictos o los dirimió de manera pacífica (María Teresa Uribe). En contraste, afirmó a manera de hipótesis que las experiencias negativas sufridas por la "proto-región" antioqueña en las guerras civiles fueron de gran importancia para darle cohesión y sentido, que las derrotas constituyeron una experiencia crucial que produjeron el efecto de una toma de distancia frente a la guerra, que esta debilidad militar reforzó la actividad económica y comercial, que esta actitud no se trató de un proyecto conciente y que el papel de la guerra en Antioquia no fue tan diferente al de el resto del país.

La obra de Botero Herrera es interesante porque presenta ajustadamente las experiencias de los antioqueños en los conflictos del siglo XIX. Su presentación inicia con el reconocimiento de la incapacidad militar antioqueña para resistir las fuerzas españolas de reconquista, incapacidad que fue una constante en la historia militar de la región; luego se centra en las vicisitudes de la rebelión de José María Córdoba en contra de la dictadura de Bolívar y que terminó con la muerte del caudillo antioqueño; después narra las incidencias del levantamiento exitoso del Coronel Salvador Córdoba en contra de los agentes de la dictadura de Urdaneta en Antioquia; y por último, su texto muestra la lucha por llenar el vacío dejado por los caudillos de la Independencia y que explica la cruenta guerra civil a inicios de los años cuarenta, guerra en la que se involucró Salvador Córdoba como Supremo de Antioquia y en la que cayó fusilado junto con su camarilla (Botero, 2003).

Según Francisco Zuluaga, respecto a la Guerra de los Supremos (1839-1841) hay varias discrepancias entre la bibliografía disponible. En cuanto a la periodización y precisión del conflicto principal existe cierta desorientación. Atendiendo a las palabras del profesor Armando Martínez, se debe subrayar que una guerra civil tiene un motivo central, una disparidad de opiniones que no permite la negociación y que se trata de un enfrentamiento armado por el poder supremo del Estado. En este sentido, la interpretación de Botero Herrera es acertada, pues en la Guerra de los Supremos se luchó por el control hegemónico del Estado y por la disparidad de opiniones sobre sus principios organizativos. Sea que se acepte la Guerra de los Conventos como antesala de la Guerra de los Supremos, o que se prefiera darla por iniciada con la declaración de guerra de Obando tras el proceso que se levantó en su contra por el asesinato de Antonio José de Sucre, lo importante aquí es señalar que aquellas fueron las justificaciones para motivar la guerra por el control del Estado. De ahí que con la declaración de la guerra restauradora de la libertad por parte de Obando, quien proclamó la defensa de la religión y de la Constitución de 1832, se inició una lucha armada por el poder y por los órdenes políticos discrepantes que canalizó la insatisfacción de las Provincias 
con el gobierno neogranadino (Zuluaga, 1998: p. 17-36).

La guerra hizo que el gobierno perdiera el control sobre dieciséis Provincias, esta circunstancia demuestra que la Guerra de los Supremos superó las incidencias del problema religioso y de las diferencias personales entre Obando y Mosquera, para transformarse en una guerra de carácter nacional en la que por poco vencen los rebeldes. Álvaro Tirado Mejía sugirió que las causas ideológicas y materiales se presentaron en todas las guerras civiles colombianas "con extraña mezcla", las contiendas no fueron uniformes en todo el territorio y sus elementos cobraron diferente significación en cada periodo o región. Tirado Mejía señaló que la Guerra de los Supremos se extendió por toda la Nueva Granada y que los Jefes Supremos crearon sus huestes y se lanzaron a la insurrección movidos por apetitos de poder, para vengar supuestos agravios y defenderse de la persecución política (Tirado, 1995: p. 12-14). Si bien, la guerra concluyó con el "fracaso absoluto" de Obando y el triunfo de Mosquera, puede decirse que este enfrentamiento cumplió funciones diferentes a las que expresó inicialmente. Los hombres y las ideas que triunfaron a corto plazo fortalecieron paradójicamente a los derrotados, que luego serían los triunfadores definitivos. La Guerra de los Supremos y el régimen de los doce años enmarcaron la alineación del pensamiento político en dos reconocidos partidos (Zuluaga, 1998: p. 32-33).

El protagonismo de las sociedades democráticas, el dominio de las tendencias liberales, la abolición de la esclavitud, las arremetidas contra la Iglesia y la exclusión de los conservadores fueron las disparidades que causaron el enfrentamiento de 1851. La insurrección conservadora en las Provincias de La Nueva Granada en contra de la administración del General López fue el resultado de la impopular exclusión de las élites tradicionales que se habían afianzado durante los doce años de gobierno conservador, fue la misma reacción que una década atrás manifestaron los progresistas en la Guerra de los Supremos. La lucha fue de nuevo por el acceso al control del Estado y por la discrepancia de las opiniones en cuanto a su forma. Para Valencia Llano la Guerra de 1851 se trató de una revuelta de señores tradicionales que vieron en peligro la continuidad de su dominio y que recurrieron a la lucha armada. La insurrección se desarrolló en escenarios y operaciones aisladas, así en Antioquia el motivó principal de la lucha fue la autonomía federal y en el Cauca se luchó por volver a imponer el dominio social que los terratenientes esclavistas venían perdiendo (Tirado, 1995: p. 12-14).

La reforma liberal en la Nueva Granada experimentó su primera fase entre 1849 y 1854 , los partidos definieron su programática durante el debate electoral que ganó José Hilario López, los liberales adoptaron una nueva Constitución (1853), abolieron los monopolios, descentralizaron la administración y esbozaron las bases para el futuro federalismo. Durante las administraciones de López y Obando se generó un enfrentamiento entre liberales moderados-militaristas (Draconianos) y liberales radicales (Gólgotas). La coyuntura alcanzó su vértice con el golpe de Estado de José María Melo (abril de 1854), ocho meses después la dictadura y los moderados fueron derrotados, quedando la vía libre para perfeccionar el liberalismo radical.

El primero de Abril de 1853 José María Obando (liberal moderado) tomó posesión de la presidencia de la Nueva Granada. Su agenda apuntó a la reforma inmediata de la Constitución, declaró inaceptable un gobierno federativo, exigió que el sufragio fuese universal y secreto, que el ejército fuese permanente, ponderó el establecimiento de las sociedades democráticas y de la libertad de enseñanza y se declaró en contra de las doctrinas de los 
socialistas franceses. Desde los primeros días de su administración se formó en el Congreso un partido de oposición con gran peso en la Cámara de Representantes, cuya bancada era mayoritariamente Gólgota, estos jóvenes radicales no querían ni moderación, ni prudencia en las reformas y sabían que Obando no compartía aquellos principios. El propósito del Congreso se centró en la discusión y acuerdo de la nueva Constitución para la República, luego de menudas discusiones entre ultra-liberales y moderados se concertó definitivamente la reforma constitucional que debilitó el Ejecutivo y descentralizó la administración.

La crisis política estalló en 1854 cuando un grupo de oficiales draconianos derrocó al presidente Obando, que en varios aspectos pertenecía a su facción, fue así como se fraguó la breve dictadura militar bajo el mando de José María Melo. La dictadura maniobró sólo con el propósito de suprimir el Congreso que en aquel momento impedía las medidas proteccionistas urgidas por los artesanos y amenazaba al ejército permanente con la actitud de la bancada Gólgota. Sin embargo, la dictadura y sus gestores fueron duramente reprimidos, la "gran coalición constitucional" entre Gólgotas y conservadores consiguió el triunfo.

En cuanto a la interpretación del golpe de Melo, Fabio Zambrano afirmó que las primeras décadas tras la Independencia constituyeron una época de tránsito de la política tradicional a la política moderna. Este proceso arrastró profundos cambios en las formas de organización social y en los imaginarios políticos, la mutación cultural producida por el advenimiento de la modernidad implicó una transmisión de la nueva cultura política que no dejo de ser conflictiva (Zambrano, 1998: p. 58-72). Para Álvaro Tirado las disparidades que originaron el enfrentamiento en 1854 señalan la culminación de una intensa agitación. Los artesanos querían medidas proteccionistas, los comerciantes el librecambismo, las masas urbanas defendían las tierras ejidales, los terratenientes trataban de apropiárselas, los gólgotas querían la abolición del ejército permanente y el resultado fue la participación de los militares en la revuelta al lado de los sectores populares (Tirado, 1995: p. 14-15).

En 1854 se enfrentaron nuevamente los grupos que querían instalarse en el dominio del Estado, fue un enfrentamiento esencialmente político por la forma, por los principios y por el control de poder supremo. La coalición Gólgota-Conservadora que consumó la derrota de Melo funcionó nuevamente durante la elección presidencial. Mediante el sufragio universal Mariano Ospina Rodríguez fue elegido presidente, al tiempo que comenzó la segunda fase de la reforma liberal con el federalismo que surgió ordenadamente durante la administración de Ospina. En adelante el enfrentamiento se dio entre los anteriormente coalicionados: liberales radicales y conservadores lucharon por su preponderancia.

Los radicales se instalaron en el poder tras su victoria en la guerra civil de 1859-1862, perfeccionaron el sistema federalista promulgando la Constitución de Rionegro (1863) en la que se optó por el nombre de Estados Unidos de Colombia. El federalismo se llevó hasta sus extremos y la doctrina liberal se desarrolló libremente, todo lo que cupo en la cabeza de un radical se hizo un hecho. Los Estados Soberanos se concibieron básicamente como Estados independientes, tenían sus propias Fuerzas Armadas, sus rentas y emitían sus sellos postales, el gobierno central se debilitó cuanto fue posible, el mandato presidencial se redujo a dos años prohibiendo la reelección inmediata.

Tirado Mejía explicó que las discrepancias que a finales de la década de 1850 llevaron a la guerra a los liberales radicales en contra del gobierno conservador, se fun- 
daron en el problema religioso y la autonomía de los Estados. "El problema de la autonomía era el del poder regional de los círculos dominantes, mucho más importante para ellos en cuanto más concreto y posible de ejercer que un difuso poder nacional" (Tirado, 1995: p. 15). Igualmente, para Armando Martínez la guerra civil de 1859-1862, iniciada en el Cauca contra el gobierno supremo de la nación, tuvo como disparidad central el problema de la soberanía de los Estados federales. Puesto que la ley electoral adelantada en el Congreso por la Administración de Mariano Ospina desequilibró los poderes de los Estados federales creados desde 1855 y sancionados constitucionalmente en 1858. La guerra arregló la disparidad a favor de los rebeldes y de la soberanía de los Estados federales, la Convención de Rionegro "perfeccionó" la obra federal redactando una Constitución de Estados soberanos unidos (Martínez, 2005) ${ }^{5}$.

La elección del Presidente Mariano Ospina coincidió con el debate de la reforma constitucional que supuestamente traería la paz a la nación con la implantación del federalismo. La reforma pretendió eliminar los males derivados del centralismo, de esta manera el Congreso dividió al país y estableció la alianza federativa conocida como la Confederación Granadina. Está claro que la reforma federal contó con la aprobación de los dos partidos en el Congreso (radicales y conservadores), pero un grupo no creyó en el proyecto y pensó que una vez puesto en práctica se desacreditaría por sí mismo, grupo que fue encabezado por el Presidente electo Mariano Ospina.

La reforma constitucional anunció profundos problemas políticos relacionados con fines electorales, además la crisis

5 Según Armando Martínez, la guerra se originó por el problema de la autonomía de los Estados federales. "Desde la perspectiva de los dirigentes del Estado del Cauca, la nueva ley electoral violaba su soberanía. Desde la perspectiva de la Administración Ospina, los Estados federales no contaban con soberanía, pues ésta seguía perteneciendo a la nación". política se agravó con el acercamiento de los liberales radicales y Mosquera, coalicionados para el apoyo del sistema federalista. Pero la disparidad central que llevó a la guerra fue la expedición de tres leyes por parte de la Administración Ospina, consideradas intervencionistas y agresoras de la autonomía de los Estados, estas fueron: la ley de estudios, la ley sobre los intendentes nacionales y la ley de elecciones. Así las cosas, Mosquera se lanzó a la guerra argumentando que el Gobierno central estaba interviniendo en los asuntos del Cauca, en julio de 1861 Mosquera triunfó sobre el gobierno conservador y se declaró presidente provisorio de los Estados Unidos de Colombia (Valencia, 1998: p. 91-104).

Según lo expuesto, la disparidad se resolvió a favor de los liberales radicales, quienes lucharon por "defender y fortalecer" la autonomía de los Estados Federales. La Constitución de Rionegro llevó el federalismo hasta sus últimas consecuencias y debilitó el poder ejecutivo hasta el máximo posible. El sector radical del liberalismo buscó con la Constitución de 1863 contener el poder de la coalición caudillista que arrebató el poder a Mariano Ospina en 1860, en adelante los enfrentamientos serían entre los coalicionados que depusieron al gobierno conservador. Valencia Llano expresó que entre las grandes transformaciones del Estado colombiano se encuentra la Constitución de 1863, la cual debilitó al Estado central para fortalecer estratégicamente los espacios de dominio de las élites provincianas mediante el reconocimiento legal. Asimismo, sugirió a manera de hipótesis que "el régimen de lealtades" que se dio alrededor de los caudillos estaba cediendo paso a "la comunidad de ideas" como elemento de identificación política y cohesión social. Finalmente, señaló que durante su hegemonía el radicalismo liberal se convirtió en un régimen absolutamente oligárquico, corrupto, excluyente y transgresor de la autonomía de los Es- 
tados (Valencia, El Estado soberano del Cauca, 1998: p. 43-68).

Durante las administraciones radicales el reparto burocrático se convirtió en un elemento de lucha constante, generó la política de "círculos" en detrimento de su "doctrinarismo" liberal. Al radicalismo le hizo mucho daño el poder, su manejo los llevó hasta atentar contra su propia obra constitucionalista que se fundó en la defensa de la soberanía de los Estados de la Unión, la nación colombiana se hundía cada vez más bajo el régimen radical. Este aspecto es fundamental para precisar las discrepancias que motivaron los enfrentamientos posteriores; para explicar las circunstancias que llevaron a los conservadores a la guerra en 1876 y determinaron la formación del Partido Liberal independiente entre 1873-1886, el cual sacó avante el programa de reorganización estatal conocido como "La Regeneración" tras la derrota del radicalismo en la guerra civil de 1885.

En cuanto a la guerra civil de 1876-1877, Armando Martínez afirma que la disparidad central que motivó el enfrentamiento fue la orientación de la educación pública en un sentido laico o católico. La exclusión de la enseñanza de la religión de las escuelas primarias inspirada en el ideario liberal desequilibró el poder de las dos potestades tradicionales (la Iglesia y el Estado), para Martínez en “esta guerra se jugó el currículo formativo de una nueva generación de colombianos" (Martínez, 2005). Sin embargo, es evidente que en la "Guerra de las Escuelas" Ios conservadores, tras un largo confinamiento, aparecieron insinuándose en el poder y que el tema de las escuelas fue sólo un pretexto. Los conservadores venían expresando su franca oposición al régimen liberal en lo concerniente al rol de la religión en la sociedad, al tema educativo y al fraude electoral por parte del gobierno de la Unión (Ortíz, 1998: p. 105-130). Con la elección de Aquileo Parra (febrero de
1876) como Presidente de la Unión la crisis política reventó, los conservadores tomaron como pretexto la cuestión religiosa, emprendieron la lucha armada en contra del gobierno y los liberales, a la sazón profundamente divididos.

La investigación de Javier Díaz sobre el faccionalismo liberal y la Guerra civil de 1876-1877 en el Estado Soberano de Santander precisó acertadamente algunas consideraciones sobre el desarrollo de la guerra y sus consecuencias. Sugirió que la unión liberal durante el conflicto fue provisional, que si bien el triunfo en la guerra representó una victoria para todo el liberalismo, terminó siendo un triunfo para el liberalismo independiente que consolidó su liderazgo en la Unión. En contraste, el liberalismo radical perdió su preeminencia y terminó entre los perdedores, porque el afianzamiento de los Independientes "llevaba consigo el germen destructor del radicalismo" (Díaz, 1999: p. 154-175). Con la llegada de Rafael Núñez a la presidencia en 1880, el Partido Liberal Independiente lideraría la obra regeneradora de la república, sólo hacia falta la estocada final contra el radicalismo, que debió esperar casi un lustro.

Tras la guerra de 1876 los radicales quedaron descolocados, mientras que los liberales independientes ganaron fuerzas. El radicalismo vio derrumbarse su poder cuando en 1878 el General Julián Trujillo, militar caucano de orientación mosquerista, conquistó la presidencia de la Unión y los desplazó del poder supremo. La causa de la derrota radical fue el desgaste en el ejercicio del poder hegemónico desde 1868 y durante una década, desgaste ocasionado por los desbarajustes provenientes de la aplicación de la Constitución de Rionegro. En definitiva, puede afirmarse que "Ios radicales salieron del gobierno aplastados por una avalancha de circunstancias" que generalizaron la crisis política, administrativa y económica en toda la república. 
En brazos de Julián Trujillo llegó Rafael Núñez a su primera presidencia en 1880, así los independientes se ratificaron en el poder supremo y los conservadores recibieron participación en el gobierno tras muchos años de relegación (España, 1985: p. 65-75).

En 1884 Rafael Núñez accedió por segunda vez a la presidencia de la Unión. Según afirmó Gonzalo España, hacia el año 84 el partido radical colombiano estuvo delante de una buena perspectiva de retorno al poder. A los radicales les favorecía el recelo y el desencanto surgido dentro de las filas del liberalismo independiente contra Núñez. Se hizo manifiesto que Núñez basó el destino de sus propósitos y su futuro político "en la tabla de salvación del partido conservador", al tiempo que los conservadores vieron en él "un puente seguro hacía la reconquista". Así las cosas, la posibilidad de impedir la victoria nuñista y el retorno de los godos dependió de la habilidad de los radicales para unificar al fragmentado liberalismo. Los jefes radicales desesperados por un pronto regreso al poder y ansiosos de vengar los atropellos del oficialismo, "decidieron jalar de la espada y jugarse el todo por el todo en una guerra a destiempo". Nuevamente la disparidad de opiniones políticas y el enfrentamiento alrededor del poder supremo del Estado motivó la guerra civil. La guerra del año 85 "fue una guerra loca que terminó en el desastre para todo el liberalismo" (España, 1985: p. 9-10).

Es indudable que al presidente Rafael Núñez le convenía una oportunidad política como la guerra para dar vía libre a sus proyectos y confinar a sus enemigos. La guerra representó su mejor oportunidad para derogar por la fuerza la mayor y más costosa entelequia del radicalismo: "la organización administrativa y política que dio al país la Carta de Rionegro". Constitución Política considerada inadecuada para Colombia y que necesitaba derogar- se para dar paso a la perentoria unidad nacional. La centralización del Estado recayó en las manos de Rafael Núñez, con él vino un fuerte régimen conservador que asentó el poder terrateniente y fortaleció la relación Iglesia-Estado, condenando las conquistas de la "revolución liberal" (España, 1985: p. 10-13) .

La insurrección de los radicales santandereanos en el año 84 se convirtió en el punto de partida de un levantamiento general y pronto la "danza guerrera" fue sacudiendo a los Estados de la Unión. Cuando se dio por sentado que la guerra sería inevitable, Rafael Núñez atendió con apuro la cuestión bélica. Su primer movimiento militar consistió en autorizar al General conservador Leonardo Canal para que conformara el ejército de reserva. Si bien, Canal fue el más distinguido militar conservador, no participó en la guerra, pero entregó a Núñez un diestro cuadro de oficiales que participaron en la confrontación con toda resolución. El éxito del gobierno en la guerra dio cuenta de la buena formación del cuerpo militar que respaldo a Núñez, imagen que contrastó con las enclenques milicias domésticas de los Estados. Mientras la frustrada insurrección no consiguió siquiera la organización de sus potenciales reservas, el ejército de Núñez logró preparar más tropas de las necesarias, pues las reservas de Canal no se desplegaron en la guerra del 85. Así, "poco a poco, por el instrumento del fuego y de la pólvora, el país retornó a la normalidad" (España, 1985: p. 192-199).

Para el segundo semestre de 1885 la victoria de Núñez estaba certificada. En agosto de aquel año la Constitución de

6 Si bien, el citado trabajo de Gonzalo España es meritorio y acertado, no deja de tener un marcado acento partidista lanzado en contra de Rafael Núñez y de los conservadores a través de un lenguaje pasional. Véase el siguiente fragmento: "Más que triunfar [el radicalismo], parece haberle interesado exclusivamente dejar constancia de su verticalidad y de su intransigencia. Perdió la partida frente a Núñez, un jugador astuto y sin principios que en medio de su desespero por sobrevivir traicionó al liberalismo en su conjunto y le entregó el mando del país a los conservadores". 
1863 fue declarada muerta por Núñez y no había ya quien la salvara. Con esta muerte el país ganó la centralización y unificación, la problemática soberanía de los Estados federales fue sustituida por un poder central inaplazable, las milicias domésticas fueron reemplazadas por un ejército de mando único en un camino hacia la profesionalización e institucionalización, las legislaciones de parroquia fueron sustituidas por un código nacional en materia económica y jurídica. La obra regeneradora de la república quedó refrendada con la Constitución de 1886. De esta forma los conservadores se instalaron a su antojo en el poder supremo del Estado; pero faltarían dos guerras más para resolver el equilibrio de poderes a favor de los conservadores, en la última década del siglo XIX los colombianos tomaron nuevamente las armas para pelear por el domino del Estado.

La Guerra Civil de los Mil Días, la última en la historia política y militar de Colombia, afianzó el programa regenerador y el dominio conservador. Fernán González afirmó que esta guerra evidenció las dificultades que la realidad social y geográfica oponía al modelo de sociedad nacional integrada, impuesto por la Regeneración (González, 2001: p. 107-123). En palabras de Marco Palacios, el proyecto político centralizador de la Regeneración no tuvo posibilidad política sino a partir de la conclusión de la guerra, después de 1904, debido a la falta de respaldo de amplios sectores de la población. Los cimientos del proyecto centralizador en un principio fueron muy endebles, pues las nuevas funciones de intervención económica directa y de control político, que la ideología de la Regeneración le atribuyo al Estado, eran imposibles sin un crecimiento económico y sin una mayor integración interna de las clases dominante. Posiblemente el triunfo conservador en la guerra de cambio de siglo aseguró a la fuerza la integración y el orden interno necesario para emprender la búsqueda del progreso en los términos en que el positivismo lo pensó. Está claro que el sentido político de las Guerras Civiles colombianas del siglo XIX no está en discusión, y la Guerra de los Mil Días no fue la excepción, pues en ella estuvieron en juego los elementos centrales del orden político del país y su disputa hegemónica entre los partidos políticos tradicionales ${ }^{7}$.

\section{Referencias}

BOTERO, F. (2003). Estado, Nación y Provincia de Antioquia: Guerras civiles e invención de la región 1829-1863. Medellín: Hombre Nuevo.

DÍAZ, J. (1999). Del faccionalismo a la unidad liberal en el ocaso del federalismo: La Guerra Civil de 1876-1877 en el Estado Soberano de Santander. Tesis para optar al título Historiador, Escuela de Historia, Universidad Industrial de Santander, Bucaramanga, Colombia.

ESPAÑA, G. (1985). La Guerra Civil de 1885: Núñez y la derrota del radicalismo. Bogotá: Áncora.

GONZÁLEZ, F. (2001). De la guerra regular de los "generales-caballeros" a la guerra popular de los guerrilleros. En: Sánchez, G. \& Aguilera, M. (Eds.), (2001). Memoria de un país en guerra: los mil días 1899-1902. Bogotá: Planeta-IEPRI.

GUERRA, F.X. (1998). De la política antigua a la política moderna: La revolución de la soberanía. En: Guerra, F.X. y Lempérière, A. Los espacios públicos en Iberoamérica: Ambigüedades y problemas. Siglos XVIII-XIX. México: Fondo de Cultura Económica.

MARTÍNEZ, A. (2005). Convocatoria a una nueva historia política colombiana: conceptos fundamentales y temas básicos. Medellín: Universidad Pontificia Bolivariana.

ORTíZ, L.J. (1998). Guerra y sociedad en Colombia 1876-1877. En memorias de la II cátedra anual de historia "Ernesto Restrepo Tirado". Las guerras civiles desde 1830 y su proyección en el siglo XX. Bogotá: Museo Nacional de Colombia - Ministerio De Cultura.

ORTíz, L.J. (2004). Fusiles y plegarias: guerra de guerrillas en Cundinamarca, Boyacá y Santander 1876-1877. Medellín: Universidad Nacional de Colombia sede Medellín.

7 Para cerrar este artículo, es sugerente citar la introducción del libro editado por Gonzalo Sánchez y Mario Aguilera, el cual interpretó las formas de hacer la guerra durante los Mil Días. Estos autores señalaron que "la guerra de los Mil Días fue una guerra masiva, sangrienta y violenta. Masiva por la magnitud no sólo de los hombres levantados en armas -más de 26 mil oficiales y suboficiales del Partido Liberal, considerando las acciones regulares e irregulares- sino también por el amplio apoyo social brindado a los contendientes. Sangrienta, por el número de víctimas y la forma de eliminación de los adversarios [...]. Nacional en tanto que fue copando, durante sus tres largos años de duración, toda la geografía colombiana y puso en el centro del debate temas como territorio, fronteras, orden político, soberanía y articulación del país al orden internacional [...]. Más allá de las peripecias de la guerra, de los argumentos partidistas y del sectarismo a menudo oscurecedor de los contenidos, en los Mil Días, como en ninguna otra de las guerras precedentes, estuvieron en juego elementos centrales del orden político y cultural" (Sánchez \& Aguilera, 2001: p. 19-21). 
SÁNCHEZ, G. (1991). Guerra y política en la sociedad colombiana. Bogotá: Ancora.

SÁNCHEZ, G. \& Aguilera, M. (Eds.), (2001). Memoria de un país en guerra: los mil días 1899-1902. Bogotá: Planeta-IEPRI.

THIBAUD, C. (2005). Formas de guerra y mutación del ejército durante la guerra de Independencia en Colombia y Venezuela. En Rodríguez, J. Revolución, Independencia y las nuevas naciones de América. Madrid: MAPFRE TAVERA.

TIRADO, Á. (1995). Aspectos sociales de las guerras civiles en Colombia. Medellín: IDEA.

VALENCIA, A. (1998). Estado Soberano del Cauca: Federalismo y Regeneración. Bogotá: Banco de la República.

VALENCIA, A. (1998). La Guerra de 1851 en el Cauca. En memorias de la ll cátedra anual de historia "Ernesto Restrepo Tirado". Las guerras civiles desde 1830 y su proyección en el siglo XX. Bogotá: Museo Nacional de Colombia - Ministerio De Cultura.

ZAMBRANO, F. (1998). El golpe de Melo de 1854. En memorias de la Il cátedra anual de historia "Ernesto Restrepo Tirado". Las guerras civiles desde 1830 y su proyección en el siglo XX. Bogotá: Museo Nacional de Colombia - Ministerio De Cultura.

ZULUAGA, F. (1998). La Guerra de los Supremos en el suroccidente de la Nueva Granada. En memorias de la ll cátedra anual de historia "Ernesto Restrepo Tirado". Las guerras civiles desde 1830 y su proyección en el siglo XX. Bogotá: Museo Nacional de Colombia - Ministerio De Cultura. 